\title{
КЕРАМИЧЕСКАЯ КОЛЛЕКЦИЯ БАРЬЯЗИНСКОГО ГОРОДИЩА ${ }^{1}$
}

\author{
(C) 2021 г. А.Г. Колонских
}

В статье дана характеристика и типология керамической коллекции Барьязинского городища. Материалом исследования являются результаты археологических раскопок В.А. Иванова в 1973-1974 гг. Большая часть коллекции представлена керамикой бахмутинской культурной группы. В значительно меньшем количестве была обнаружена керамика ананьинской, пьяноборской и мазунинской культур. В работе приведены основные признаки гончарной традиции населения бахмутинской культуры, в соответствии с морфологией форм, составом формовочных масс, фактурой и орнаментом сосудов. Керамика бахмутинской культурной группы довольно однородна, как в пределах изучаемого памятника, так и на всей территории распространения культуры. Локальные особенности поселенческой керамики, чаще всего выражаются в различиях состава формовочных масс. На примере керамики Барьязинского городища, автору удалось проследить вероятные векторы влияния инокультурных традиций на гончарство бахмутинской культуры.

Ключевые слова: археологическая керамика, бахмутинская культура, мазунинская культура, городище, ананьинская культура, пьяноборская культура, Уфимско-Бельское междуречье.

\section{CERAMIC COLLECTION OF BARYAZA HILLFORT ${ }^{2}$}

\section{A.G. Kolonskikh}

The paper features the characteristics and typology of the ceramic collection from Baryaza hillfort. The material of the study is the results of archaeological excavations carried out by V.A. Ivanov in 1973-1974. The major part of the collection is represented by ceramics of the Bakhmutino cultural group. Ceramics of the Ananyino, Pyany Bor and Mazunino cultures have been found in considerably smaller quantities. The paper presents the main features of the pottery tradition of the Bakhmutino culture, based on the morphology of the forms, composition of the molding masses, texture and ornament of the vessels. The ceramics of the Bakhmutino culture is rather homogeneous, both within the studied site and throughout the territory of the culture's spread. Local features of the hillfort ceramics and most frequently expressed in the composition of molding materials. Using the example of the ceramics from Baryaza hillfort, the author was able to trace the likely influence vectors of foreign cultural traditions on the pottery of the Bakhmutino culture.

Keywords: archaeological ceramics, Bakhmutino culture, Mazunino culture, hillfort, Ananyino culture, Pyany Bor culture, Ufa-Belaya interfluve.

Основная цель работы - характеристика керамической коллекции Барьязинского городища - памятника примечательного, как с точки зрения топографии, так и в плане археологического материала, обнаруженного в культурном слое. Поселение не единожды становилось предметом полевых исследований, в основном разведочных. Стационарные раскопки памятника проведены В.А. Ивановым в 1973-1974 гг. ${ }^{1}$

Актуальность исследования продиктована слабой степенью опубликованности материалов поселенческих памятников в регионе Уфимско-Бельского междуречья. Настоящая публикация, является продолжением иссле- дования автора, посвященного керамическим традициям населения Южного Предуралья в эпоху раннего железного века - раннего средневековья. Особое внимание в работе уделяется характеристике гончарных традиций бахмутинского населения, потому как основной материал городища относится именно к указанной культуре.

Городище Барьязы (Барьязинское городище, «Попова горка») расположено на правом берегу р. Быстрый Танып, в 350 м южнее д. Барьяза на останце, образованном в ходе меандрирования древнего русла реки. Размеры останца: длина около 450 м, ширина 40-50 м, высота от уровня подошвы достигает

Работа выполнена в рамках реализации государственного задания АААА-А21-121012290083-9 в сфере научных исследований.

2 The work was completed within the framework of the implementation of the state assignment AAAA-A21-121012290083-9 in the field of scientific research. 
15 м. У северной оконечности, а также вдоль восточной стороны протекает небольшая речка, которая носит название Барьязинка. Останец, на котором расположено городище, местные жители называют «Попова горка», на топографических картах данная местность называется «урочище Гора Попова» (Колонских, 2017, с. 19-23).

Городище открыто в 1964 г. Ю.А. Морозовым в ходе разведочных работ в бассейне р. Быстрый Танып (Морозов, 1964, с. 2-3). В юго-восточной части площадки городища, была обнаружена керамика бахмутинской культуры, а также человеческие кости. O находках (во время добычи алебастра на площадке объекта археологии) костей человека на городище информировали Ю.А. Морозова и местные жители.

В ходе проведенной Ю.А. Морозовым разведки в 100-150 м к западу от городища также обнаружено Барьязинское селище. Площадь памятника, по данным исследователя распахивается. На общей площади 80 х 30 м было обнаружено 34 мелких фрагмента керамики. Обнаруженная керамика схожа с керамикой, найденной на городище Барьязы.

В 1973-1974 гг. археологические исследования на городище проводились В.А. Ивановым. За два года раскопками было исследовано 138 кв. м площади памятника (Иванов, 1975). Коллекция предметов, собранная на городище, содержит фрагменты керамики, костей, куски шлака, глиняные пряслица, фрагмент железного ножа и костяной наконечник стрелы. В ходе исследования обнаружено 1110 фрагментов керамики, из них по фрагментам венчиков автором раскопок реконструировано 430 сосудов, в составе которых выделено три культурных типа:

1. ананьинский, с характерным шнуровым орнаментом и примесью раковины (14 сосудов);

2. пьяноборский, открытые чаши с примесью раковин, украшены рядом круглых ямок по шейке, поверхность некоторых сосудов залощена (70 сосудов);

3. бахмутинский (346 сосудов) - открытые чаши с примесью песка и мелкой гальки. По характеру орнамента выделяется группа ранних сосудов (43 фрагмента), украшенные рядом круглых ямок по шейке в сочетании с ёлочнообразными насечками по плечикам.
Вторая группа - поздние сосуды (303 сосуда), украшены круглыми ямками, беспорядочно разбросанными по всему тулову. Некоторые сосуды этой группы имеют косые насечки по венчику.

Из других предметов материальной культуры на городище обнаружены 4 глиняных пряслица, два целых и два в обломках, фрагмент железного ножа, круглая бляха из листовой бронзы со сквозным отверстием в центре. Костяной наконечник стрелы и брусковидный предмет из кости, неизвестного назначения. Материалы раскопок хранятся в археологических фондах ИЭИ УФИЦ РАН под номером 770 (Барьязинское городище) и по данным из книги поступлений содержит 780 предметов. В ходе проведенной сверки обнаружено 745 единиц хранения.

В 1988 г. памятник осмотрен Б.Б. Агеевым (Агеев, 1989, с. 20-21, 32) (рис. 1, 3). В 2010 г. разведочные работы на городище были проведены И.М. Акбулатовым в рамках инвентаризации объектов археологического наследия Республики Башкортостан (Акбулатов, 2010, с. 7-8, рис. 14-24). Данных об археологическом материале в отчётах не обнаружено.

Наиболее свежие данные получены в 2015 г., в ходе осмотра памятника автором публикации (Колонских, 2017, с. 19-23). На памятнике был собран подъемный археологический материал. Важным наблюдением является наличие, выраженного эскарпированного участка по западному склону останца. Фортификация городища представляет собой 4 линии укрепления. Первая (внешняя) расположенная в северной части в 15 м от разрушенного участка северного склона останца, представлена валом высотой 2-2,5 и шириной 5 м. Ров перед валом сильно оплыл и не прослеживается. Конструкция вала, вероятно, имела вид эскарпированного естественного возвышения площадки памятника, и организованной на её поверхности насыпи. Второй вал, расположен в 45 м южнее первого, он имеет высоту 3 м. от основания рва и ширину около 7 м. Ров перед валом сильно оплыл, и глубина его не превышает 0,3-0,4 м. Третий вал имеет высоту 3-3,5 м перед ним сохранился ров глубиной 0,5 м и шириной 4 м. Длина вала около 45 м. Данная линия укреплений является более традиционной и широко распространенной в Приуралье. Ров, пересекая всю площадку памятника, 


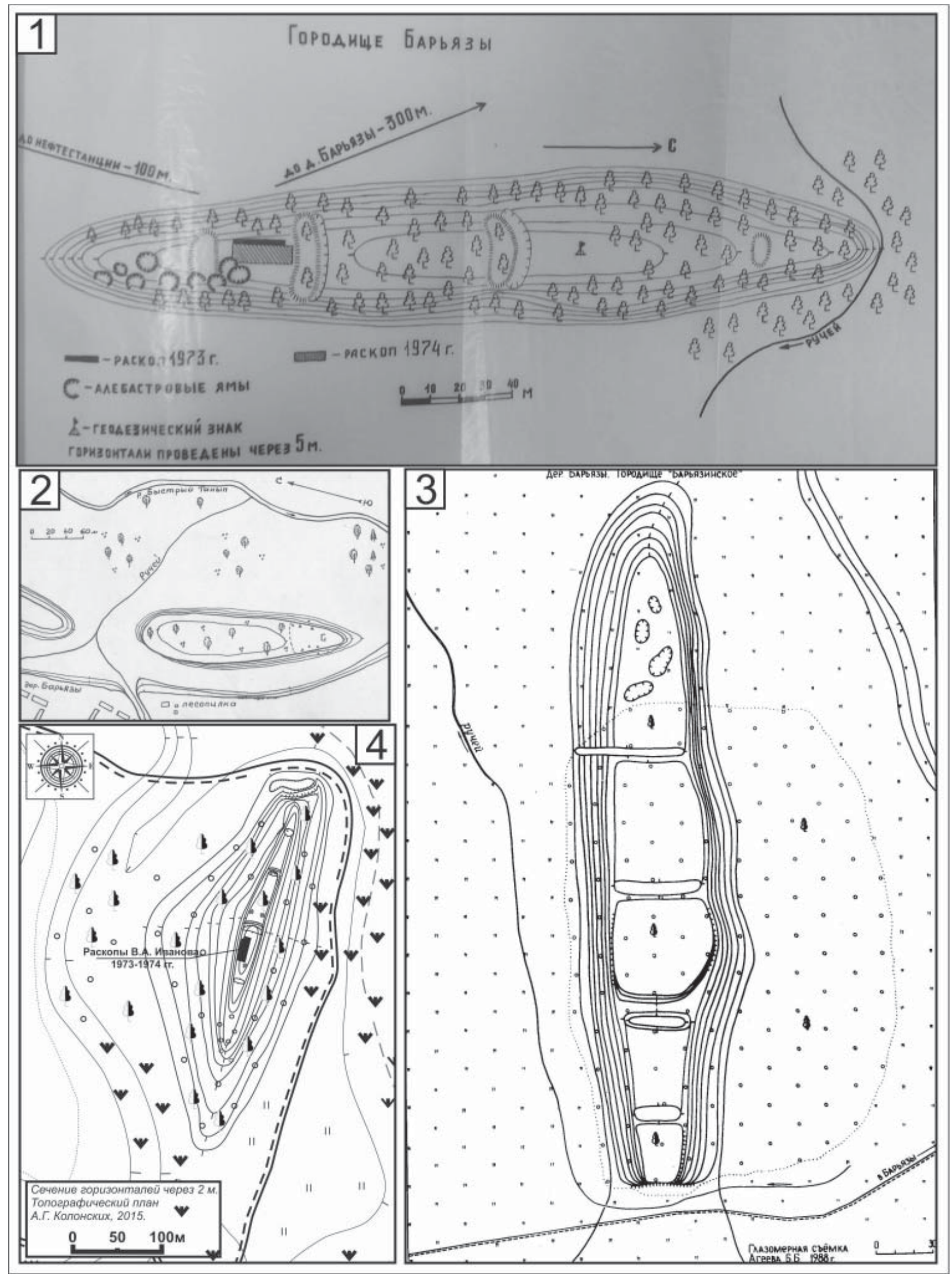

Рис. 1. Топографические планы Барьязинского городища. 1. План В.А. Иванова (1975);

2. План Ю.А. Морозова (1965); План Б.Б. Агеева (1989); План А.Г. Колонских (2017)

Fig. 1. Topographic plans of Baryaza hillfort. 1. Plan by V.A. Ivanov (1975); 2. Plan by Y.A. Morozov (1965); Plan by B.B. Ageev (1989); Plan by A.G. Kolonskikh (2017)

параллельно валу, спускается по западному склону останца. Четвертый вал имеет сохранившуюся высоту 1,5 м. Ров перед ним фиксируется очень слабо и едва заметен.
Предложенная далее характеристика и типология керамической коллекции Барьязинского городища в основном произведена на материале раскопок В.А. Иванова 1973- 
1974 гг. К настоящему времени коллекция содержит 739 фрагментов керамики. Из них: 427 орнаментированных и 84 неорнаментированных верхних частей сосуда, 179 орнаментированных и 45 неорнаментированных стенок и 4 фрагмента днищ. Часть коллекции не имеет сопровождающей документации в виде полевой, либо коллекционной описи. Данные о планиграфическом и стратиграфическом залегании находок известны для 279 фрагментов керамики.

Ввиду выраженной однообразности керамической серии представленная типология основывалась на культурной атрибуции керамики. Дифференциация ведущих типов произведена в ходе их визуального осмотра, на основе морфологии форм и пропорций сосудов, фактуре и орнаментации. Состав формовочных масс определялся в ходе наблюдения по свежим изломам фрагментов керамики, с помощью бинокулярного микроскопа МБС-10. Для реконструкции форм из общего количества керамики выделено 306 сосудов (316 фрагментов).

Исследуемая коллекция представлена 739 фрагментами керамики, из них орнаментировано 600 фрагментов. Культурную принадлежность удалось установить в 543 случаях. На основании орнамента, примеси и морфологии форм фрагментов выделены культурные группы: бахмутинская - 500 фрагментов, ананьинская - 20, пьяноборская - 11 и мазунинская - 12 фрагментов. Чаще всего орнамент представлен ямочными вдавлениями (наколами) круглой формы - 540 случаев, из них 276 по всему тулову (бессистемно, либо в виде горизонтальных и/или вертикальных рядов). В 131 случае сохранность фрагментов не позволяет достоверно установить характер и локализацию орнамента, то есть были нанесены круглые ямочные наколы, нанесены по венчику или по всему тулову. Сочетание ямочного орнамента с насечками по венчику, ёлочным, шнуровым, гребенчатым и вдавлениями различной формы встречено на 133 фрагментах сосудов. Случаи с орнаментом в виде наколов (ямок) подпрямоугольной, подовальной, подтреугольной формы, либо бесформенными вдавлениями крайне редки и в сумме составляют 24 фрагмента, 4 фрагмента сочетают вдавления и насечки по венчику, в остальных 10 - не круглые вдавления составляют композицию с круглыми ямками. Последние можно сопоставить с аналогичным поясом ямок по венчику в сочетании с ёлочным орнаментом. Исключительно насечками по краю устья орнаментированы 27 фрагментов сосудов. Единичными являются фрагменты, украшенные отпечатком шнура (3), гребенчатым (5), либо ёлочным (9) орнаментом.

Ананьинская культурная группа (рис. 2: 1-4) объединяет относительно профилированные сосуды со слабо отогнутой шейкой и выраженным переходом в тулово (в ряде случаев в виде ребра). В состав группы вошли 20 фрагментов, из них 8 сосудов позволяют реконструировать их форму, два фрагмента представлены стенками. Все фрагменты имеют примесь раковины. Край устья чаще всего округлый (в 6 случаях), уплощен (6 случаев), у 6 сосудов край с уступом («г»-образный). Поверхность всех фрагментов хорошо обработана и заглажена.

В восьми случаях сосуды орнаментированы горизонтальным поясом круглых ямочных вдавлений по шейке и оттисками шнура, шесть фрагментов только пояском круглоямочных вдавлений, в трёх случаях только оттиском шнура. Встречен сосуд украшенный, наряду с ямочным орнаментом, двойным зигзагом из оттиска гребенчатого штампа (рис. 2: 1), другой сосуд имеет поясок ямок по шейке и пять горизонтальных рядов оттиска гребенчатого штампа, а также пояс из подковообразных фигур, выполненный оттиском шнура (рис. 2: 2). Один фрагмент, принадлежащий сосуду миниатюрных пропорций украшен пояском из тройных ямочных вдавлений и зигзагообразным оттиском шнура под ним.

Пьянобрская культурная группа (рис. 2: 5-8) условно выделена по 11 фрагментов сосудов. Среди сосудов встречено 3 чашевидных. На основании форм можно выделить два условных типа - горшки, с относительно высокой слабо отогнутой шейкой и слабопрофилированным переходом в тулово и чаши. Примесь всех фрагментов - раковина, срез устья плоский (10 случаев), у одного сосуда с уступом, поверхность всех хорошо обработана, но не имеет следов лощения. Орнамент представляет собой горизонтальный пояс округлых ямочных вдавлений по шейке. 


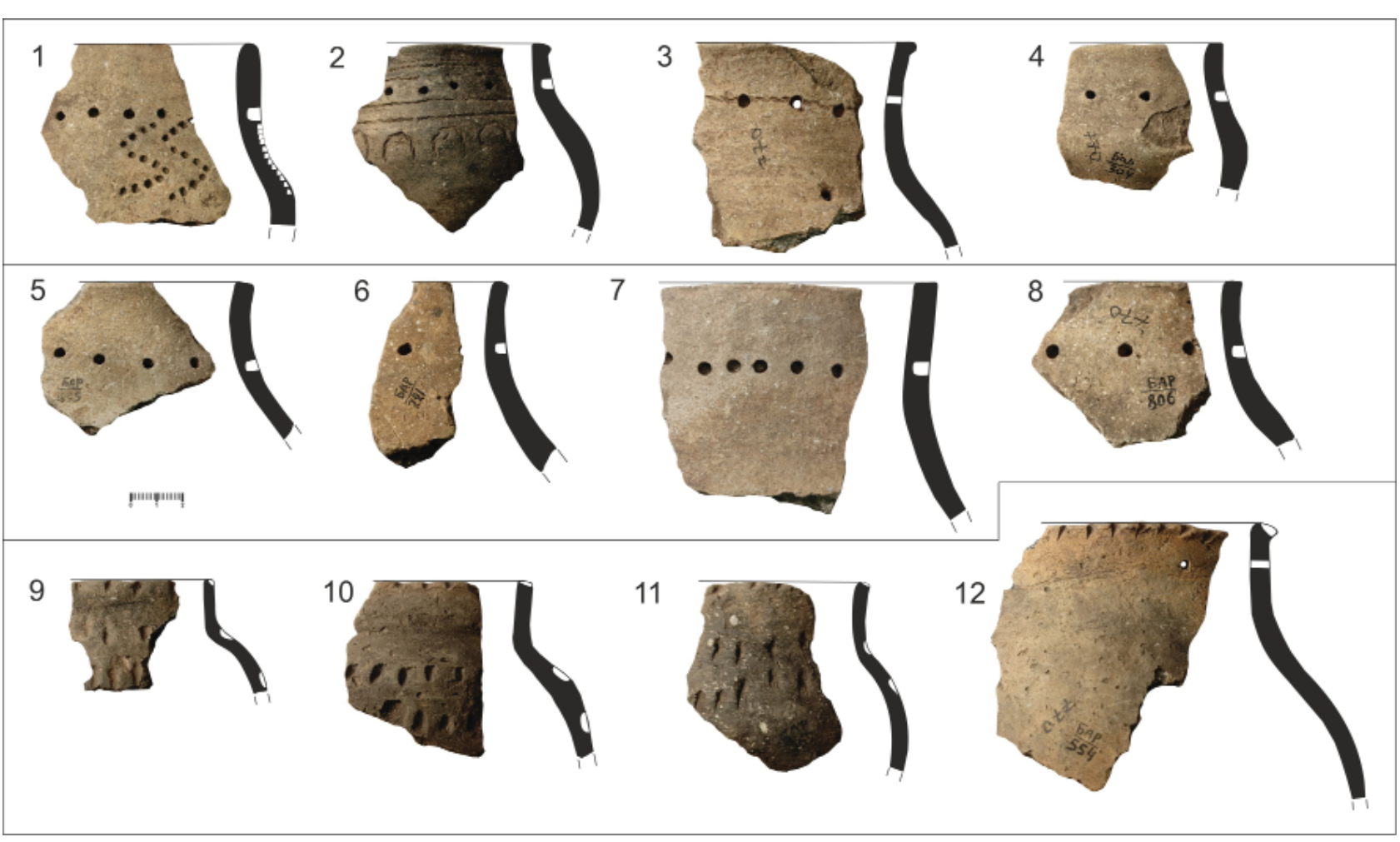

Рис. 2. Культурные группы керамики: 1-4 - ананьинская, 5-8 - пьяноборская, 9-12 - мазунинская Fig. 2. Cultural groups of ceramics: 1-4 - Ananyino, 5-8 - Pyany Bor, 9-12 - Mazunino

Керамика данной культурной группы мало чем отличается от предыдущей, основным отличием выступает отсутствие ребра по тулову и оттиска шнура, которые более характерны для сосудов ананьинской гончарной традиции.

Мазунинская культурная группа (рис. 2: 2-12) объединяет 12 фрагментов (10 сосудов), 5 из которых являются фрагментами верхних частей, орнаментированных насечками по венчику, а также несколькими горизонтальными рядами продолговатых (подпрямоугольных, либо подтреугольных) вдавлений по шейке.

Все сосуды кроме одного имеют примесь раковины, один примесь песка, в двух случаях край устья уплощен, в остальных - округлый, у одного сосуда встречены отпечатки тонких волокон в верхней части сосуда.

Подтип 1 составили сосуды с короткой, прямой, отогнутой шейкой и выраженным переходом шейки в тулово (рис. 2: 9-11).

Подтип 2 - один сосуд с высокой, прямой, отогнутой шейкой и слабовыраженным плечом (рис. 2, 12).

Абсолютное большинство материалов коллекции представлено 500 фрагментами, из которых 137 позволяют реконструи- ровать форму сосудов. Данная культурная группа соотносится с гончарными традициями населения бахмутинской культуры и находит наибольшие аналогии с подобными памятниками в Уфимско-Бельском междуречье (рис. 3-4). В большинстве случаев сосуды украшены по шейке, плечу (при наличии выраженного перехода) и тулову орнаментом в виде круглых наколов (ямок). Данный узор имеет несколько видов, чаще это хаотичное расположение по всему сосуду, горизонтальный ряд ямок по венчику и хаотичное его расположение по тулову, либо взаимно вертикальные/горизонтальные ряды по тулову. В редких случаях ямочные наколы имеют треугольную форму, встречаются единичные экземпляры с наколами подквадратной формы.

Наряду с указанным орнаментом в бахмутинскую группу включены сосуды с так называемым «ёлочным» орнаментом, который встречается в сочетании с горизонтальным рядом круглых ямочных вдавлений по верхней части, а также в сочетании с бессистемно расположенными круглыми наколами (рис. 4: 18-19).

Менее ординарными являются сосуды со следами оттисков гребенчатого штампа 


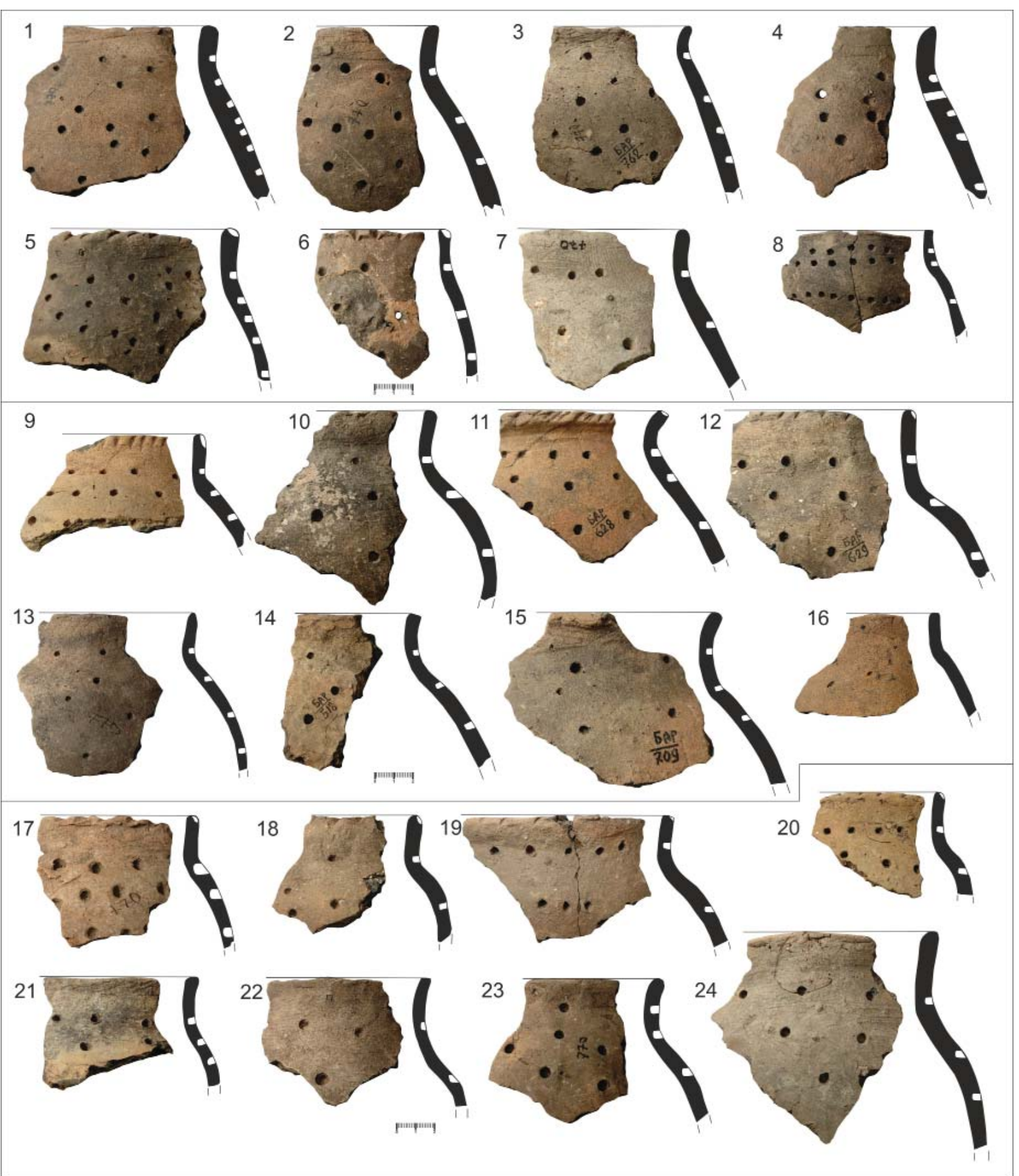

Pис. 3. Бахмутинская культурная группа: $1-8$ - тип 1, 9-16 - тип 2, 17-24- тип 3.

Fig. 3. Bakhmutino cultural group: 1-8 - type 1, 9-16-type 2, 17-24-type 3

(рис. 4: 21-24). Гребенчатый орнамент, в виде единичных случаев, встречается в материалах большинства поселений бахмутинской культуры и обычно сопровождается узором в виде круглых ямочных вдавлений, в том числе бессистемных по всему тулову.

Определение фрагментов нижних частей сосудов данной культурной группы (как и остальных) весьма затруднительно, во-первых, в виду того, что днища вероятно были округлые, либо уплощенные, а потому при сильной фрагментации керамического материала их отличия от стенок минимальны. Во-вторых, несмотря на то, что бахмутинские сосуды украшены как по верхней части, так и по тулову, встречаются фрагменты, полностью орнаментированных (рис. 4: 27).

Состав формовочных масс керамики бахмутинской культуры представлен введением непластичного сырья в виде окатанного и 
неокатанного (нередко именуемый исследователями как дресва) песка мелкой, средней и крупной фракций и, вероятно дресвой. Одним из ярких признаков - наличие фрагментов крупного песка, который встречается в литературе как «камушки» или «галька». Значительно реже, встречается сочетание песка и раковины. В отличие от керамики раннего железного века (ананьинской и пьяноборской культуры), для керамики бахмутинской культуры характерны некалиброванные фрагменты раковины, аналогичная ситуация применима и к примеси песка.

Сосуды обычно имеют следы заглаживания, нередко выраженные в виде расчёсов. Внешняя поверхность чаще всего обработана лучше, чем внутренняя. В верхней части на керамике бахмутинской культуры встречаются отпечатки тонких волокон.

Морфология форм позволяет выделить девять типов сосудов.

Тип 1. Сосуды, имеющие короткую слабо отогнутую шейку, переход в тулово слабо профилирован (рис. 3: 1-8). В состав типа объединены 34 сосуда (35 фрагментов). У большинства сосудов (24 фрагмента) срез устья округлый (рис. 3: 1-2, 3, 7), в 4 случаях уплощенный (рис. 3: 8), 3 сосуда имеют заостренный срез (рис. 3, 4). В 32 случаях формовочные массы имеют примесь некалиброванного песка, 2 сосуда имеют примесь некалиброванной раковины. У 13 фрагментов с внутренней стороны зафиксированы выпуклости («жемчужины»), возникшие в ходе нанесения ямочного орнамента, нередко они уплощены гончаром и имеют следы отпечатков пальца. Следы тонких волокон на верхних частях сосуда встречены у 23 фрагментов (рис. 3: 1-2, 3, 5). У 7 фрагментов встречены следы сквозных отверстий (рис. 3: 4, 6).

Основываясь на специфику орнаментации, условно можно выделить два подтипа - с насечками по срезу устья (рис. 3, 5-6) и без них (7 и 27 сосудов соответственно).

Тип 2. Сосуды с невысокой прямой или слабо отогнутой шейкой и резким переходом в выраженное плечо (рис. 3: 9-16). Состав типа представлен 26 сосудами. В 15 случаях верхний срез устья округлый (рис. 3: 10, 15-16), в 7 случаях уплощенный (рис. 3: 14), 2 фрагмента заостренные (рис. 3: 13). Примесь непластичного сырья в виде некалиброванного песка встречена в 21 случае, 3 сосуда имеют примесь раковины, 2 фрагмента - песок и шамот. Выпуклости «жемчужины» с внутренней стороны встречены у 4 сосудов. Следы тонких волокон в верхней части сосуда имеют 20 фрагментов, сквозные отверстия встречены 5 сосудах.

Подтипы выделяются на основе различий в орнаменте:

насечки по венчику (16 фрагментов) (рис. 3, 9,11-12);

без насечек (9 фрагментов) (рис. 3: 10, 13-15);

неорнаментированные сосуды (1 фрагмент) (рис. 3: 16).

Тип 3. Сосуды с относительно прямой или слегка отогнутой шейкой, имеющие профилированный переход в тулово в виде выраженного плеча (рис. 3: 17-24). В данный тип объединены 22 сосуда (23 фрагмента). Среди них: 12 имеют округлое оформление устья (рис. 3, 21, 23), 8 уплощенное (рис. 3, 22), 3 заостренное (рис. 3, 24). Основным составом непластичного сырья в формовочных массах сосудов данного типа в 19 случаях является некалиброванный песок, в 2 случаях раковина, встречен также один фрагмент с примесью песка и шамота. «Жемчужины» с внутренней стороны сосуда встречены дважды. Следы тонких волокон по верхней части сосуда встречены у 14 фрагментов. Сквозные отверстия обнаружены на трех сосудах.

Сосуды с оформленным насечками венчиком представлены 7 экземплярами, 15 фрагментов не имеют следов насечек. Один из фрагментов не имеющий насечек по венчику имеет подквадратную форму ямочных вдавлений.

Тип 4. Сосуды данного типа обладают высокой слабопрофилированной шейкой, имеющей наклон во внутреннюю часть сосуда (рис. 4: 1-8). Иногда край устья отогнут наружу (рис. 4: 3, 7, 8). Данный тип встречается в литературе как сосуды «закрытого типа» (Останина, 1997, с. 100). В общей сложности выделено 30 подобных сосудов (31 фрагмент). Пять из них имеют уплощенный срез устья (рис. 4, 1), два заостренный (рис. 4: 4, 6), 11 фрагментов имеют округлое оформление среза устья (рис. 4: 2, 5, 7), 12 сосудов имеют «Г-образный» (с отгибом) край (рис. 4: 3, 8). Основной примесью к глине является песок, 


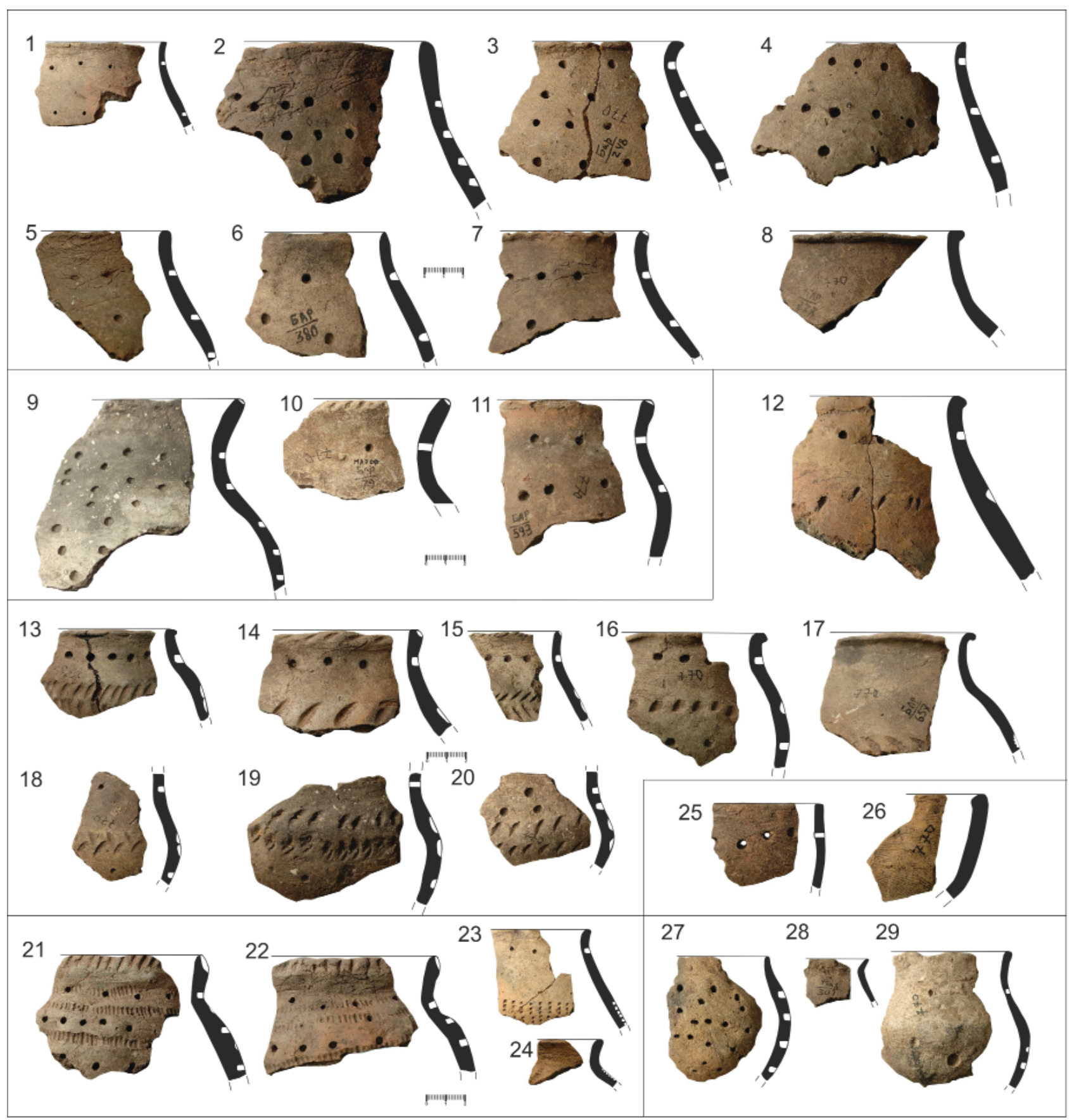

Рис. 4. Бахмутинская культурная группа: 1-8 - тип 4; 9-11 - тип 5;

12-20 - тип 6; 21-24 - тип 7; 25-26 - тип 8; 27-29 - тип 9

Fig. 4. Bakhmutino cultural group: 1-8 - type 4; 9-11 - type 5;

12-20 - type $6 ; 21-24$ - type 7;25-26 - type 8;27-29 - type 9

при этом 4 фрагмента имеют примесь раковины. «Жемчужины» с внутренней стороны орнамента зафиксированы в пяти случаях. Отпечатки волокон имеются у двух сосудов. Сквозные отверстия имеют 8 фрагментов.

Орнамент большей части сосудов представлен круглыми ямочными вдавлениями, один сосуд наряду с ямочным орнаментом имеет насечки по венчику (рис. 4: 7), один сосуд украшен исключительно насечками по венчику (рис. 4: 8).
Тип 5. Представлен сосудами с высокой, отогнутой шейкой и выраженным переходом в тулово в виде плеча (рис. 4: 9-11). В состав данного типа вошли фрагменты трёх сосудов. В формовочных массах одного фрагмента встречена раковина (рис. 4: 9), два других имеют примесь песка. У двух фрагментов обнаружены следы отпечатков тонких волокон в верхней части (рис. 4: 9, 11). Два фрагмента имеют сквозные отверстия (рис. 4: 10-11). 
Все имеют насечки по венчику, срезы устья округлые. Один фрагмент не имеет орнамента, кроме насечек по венчику (рис. 4,10$)$, два сосуда наряду с украшенным венчиком орнаментированы беспорядочными круглыми вдавлениями (наколами).

Тип 6. Основной отличительной чертой и наиболее ярким признаком данного типа является наличие ёлочного орнамента (рис. 4, 13-20). Часто этот элемент встречается с горизонтальным поясом круглых ямочных вдавлений по верхней части сосудов, при этом, в коллекции Барьязинского городища встречены сосуды, орнаментированные ёлочным орнаментом и бессистемными, либо вертикальными или горизонтальными рядами округлых наколов. Подобные примеры не единичны и встречаются на других памятниках бахмутинской, культуры, как в культурном слое поселений, так и в погребениях (Колонских, 2020, с. 78, рис. 3, 2; Мажитов, 1960, таб. 64, 2-3; таб. 69, 2).

В состав типа включены 16 сосудов (18 фрагментов) из них 9 (11 фрагментов) позволяют реконструировать их форму.

Подтип 1. Имеет высокую слабоотогнутую шейку с наклоном внутрь сосуда и слабопрофилированный переход в тулово (2 сосуда, 3 фрагмента) (рис. 4, 12-13). Срез устья с уступом («Г»-образный). Орнамент ямочный, в сочетании с подтреугольными насечками. По форме данный подтип аналогичен типу 4 , бахмутинской культурной группы. Основная примесь - песок. Отсутствуют отпечатки тонких волокон.

Подтип 2. Профилированные сосуды с невысокой слабо отогнутой шейкой и плечом (рис. 4: 14-16). Ёлочный орнамент нанесен по плечу сосуда. Объединяет 6 сосудов (7 фрагментов). У двух сосудов срез устья уплощен, у двух других округлый и украшен насечками (рис. 4, 14-15). Оставшиеся два сосуда имеют оформление среза устья с уступом (рис. 4: 16). Все фрагменты подтипа имеют примесь песка. Пять сосудов имеют отпечатки волокон по верхней части. На двух фрагментах встречены сквозные отверстия.

Подтип 3. Состоит из фрагмента одного сосуда с высокой отогнутой внутрь шейкой и выраженным переходом в тулово в виде плеча (аналогичен типу 5 данной культурной группы) (рис. 4: 17). Срез устья «Г»-образный.
Фрагмент имеет примесь песка и отпечатки волокон. Орнамент представлен насечками по венчику и ёлочным орнаментом.

Фрагменты семи стенок (рис. 4, 18-20) имеют характеристики подобные сосудам, описанным выше. Две из них наряду с ёлочным орнаментом украшены беспорядочными круглыми наколами (рис. 4, 18-19). У одного из фрагментов ёлочный орнамент нанесен оттиском тонкого продолговатого гребенчатого штампа, в остальных случаях насечки подовальные, либо подтреугольные и подпрямоугольные.

У пяти фрагментов стенок данного типа примесь в формовочных массах представлена песком, у двух - раковиной.

Тип 7. Сосуды отличительной чертой которых является наличие гребенчатого орнамента (рис. 4: 21-24). В состав данного типа вошли 4 сосуда (7 фрагментов). Среди сосудов данного типа, в соответствии с морфологическими различиями, выделено три подтипа.

Подтип 1. Это два сосуда с невысокой отогнутой шейкой и профилированным переходом в тулово, в виде плеча (рис. 4: 21-22). Край устья округлый, примесь - песок. В верхней части сосудов имеются отпечатки тонких волокон. Орнамент представлен круглыми ямочными наколами (расположенными горизонтальными линиями по всему тулову), чередующимися с горизонтальными поясами оттиска гребенчатого штампа (возможно в виде подражания отпечатку шнура). Венчики украшены косой насечкой.

Подтип 2. Сосуд с высокой наклоненной внутрь шейкой, отогнутым наружу венчиком и ребром в месте перехода в тулово (рис. 4: 23). Фрагменты имеют следы тонких волокон, основная примесь - мелкий песок. Орнамент представлен горизонтальным поясом круглых ямочных вдавлений по шейке и вертикальными оттисками гребенчатого штампа, образующему горизонтальный пояс по ребру сосуда.

Подтип 3. Фрагмент сосуда с короткой сильно отогнутой шейкой (рис. 4, 24). Примесь представлена песком, имеются отпечатки волокон. Сохранность не позволяет определить общую композицию орнамента, при этом хорошо фиксируется оттиск гребенчатого орнамента.

Тип 8. Данный тип составили чашевидные сосуды (рис. 4: 25 - 26). Подобные формы не 
Таблица 1. Данные о глубине залегания культурных групп керамики

Table 1. Data on the depth of occurrence of the cultural groups of ceramics

\begin{tabular}{|c|c|c|c|c|c|}
\hline & ананьино & пьяноборье & мазунино & бахмутино & Всего \\
\hline Горизонт 1 & 3 & 2 & 1 & 143 & 149 \\
\hline Горизонт 2 & 3 & 1 & 0 & 33 & 37 \\
\hline Всего & 6 & 3 & 1 & 176 & 186 \\
\hline
\end{tabular}

характерны для гончарных традиций бахмутинского населения, однако примесь в виде песка, обработка поверхности, а также наличие отпечатков волокон, позволили включить две чаши в состав настоящей культурной группы. При этом один из фрагментов имеет круглоямочный орнамент.

Тип. 9. Составляют фрагменты трёх миниатюрных сосудов (рис. 4, 27-29). Все они имеют примесь песка и следы волокон. Два фрагмента украшены круглыми ямочными наколами, один орнамента не имеет.

Таким образом, полученные данные позволяют утверждать, что укрепленное поселение использовалось населением начиная с эпохи раннего железного века. Наиболее активное использования площадки памятника приходится на эпоху Великого переселения народов, населением бахмутинской археологической культуры. Это подтверждают имеющиеся стратиграфические наблюдения. Важным моментом является тот факт, что керамика бахмутинского типа, будучи самой многочисленной, всё же чаще встречена в первом горизонте.

Далее хотелось бы более подробно остановится на характеристике некоторых признаков керамики Барьязинского городища. Фрагменты сосудов ананьинской, пьяноборской и мазунинской культурных групп немногочисленны, а потому полученные наблюдения не могут быть подтверждены массовым материалом. Гончарная традиция бахмутинской культуры напротив вполне представительна.

В полевой описи Барьязинского городища, В.А. Иванов отмечает, что было оставлено (вероятно, на месте полевых работ) 924 фрагмента керамики, из них с раковиной 176 фрагментов, что в принципе соответствует распределению керамики по примесям в исследуемой коллекции. Можно предположить, что оставлена была наименее информативная и неорнаментированная керамика.

Исходя из полученных наблюдений такие элементы орнамента, как вдавления различ- ной формы по плечику и насечки по венчику, являются характерными для посуды мазунинской культурной группы. Территория распространения поселений с подобной керамикой - правобережье р. Камы (удмуртская группа по Т.И. Останиной) (Останина, 1997, с. 173). Ямочно-шнуровой и шнуровой орнамент характерен сосудам ананьинской гончарной традиции. Ямочный, чаще в виде горизонтального ряда круглых ямок по верхней части сосуда - для посуды пьяноборской культуры. Данные выводы основываются на общепринятых исследователями характеристиках керамики эпохи раннего железного века (Бугров, 2006, с. 93-94; Овсянников, 2009, с. 218, 220). При этом стоит заметить, что не всегда степень изученности гончарных традиций позволяет точную идентификацию керамического материала поселений Уфимско-Бельского междуречья. Ярким тому примером является посуда ананьинской и пьяноборской археологических культур, признаки которой, в случае фрагментированности материала и его малочисленности не позволяют их точной дифференциации. В некотором смысле, данная проблема касается гончарных традиций мазунинского населения Среднего Прикамья и бахмутинского в Уфимско-Бельском междуречье. С целью попытаться приблизится к решению этой проблемы, необходимо остановиться на более детальной характеристике гончарных традиций бахмутинской археологической культуры.

Орнамент в виде круглых ямочных вдавлений встречен на 486 (97,20\%) фрагментах керамики, на $276(55,20 \%)$ из них круглые ямки составляют композицию покрывающую всю поверхность сосуда (нет достоверных данных об орнаментации днищ) бессистемным расположением, расположением горизонтальными и/или вертикальными рядами, либо описанным выше способом в сочетании с горизонтальным поясом круглых ямочных наколов по верхней части сосуда. На наш взгляд, все эти варианты принадлежат одной традиции и являются одним из наиболее ярких 
маркеров керамики поселений бахмутинской культуры в Уфимско-Бельском междуречье. В $112(22,40 \%)$ случаях композицию орнамента сосуда не позволяет реконструировать сохранность фрагментов. Наличие ямочного орнамента в сочетании с насечками по венчику встречено 35 (7,00\%) раз, 28 (5,60\%) фрагментов позволяют утверждать, что наиболее распространенный вид орнаментальной композиции на них (бессистемный ямочный), сопровождался насечками по венчику. Менее многочисленной является композиция, включающая сочетание горизонтального пояса круглых ямочных вдавлений по венчику и горизонтального ёлочного орнамента по тулову (либо по плечу или ребру, при наличии) - 15 (3,00\%), а также исключительно ёлочного орнамента - 9 (1,80\%). Очень схожей, а возможно и аналогичной предыдущей, является композиция, сочетающая горизонтальный пояс круглых ямочных вдавлений по венчику и горизонтальный пояс подовальных, подтреугольных, каплевидных или бесформенных вдавлений по тулову, встреченная на $10(2,00 \%)$ сосудах. Её отличие от ёлочного орнамента выражено не только в форме вдавлений, но и в их количестве, так как нередко данные вдавления образуют горизонтальный пояс одиночных наколов (насечек). Важным наблюдением является наличие двух (0,40\%) фрагментов сосудов, сочетающих ёлочный орнамент и бессистемный круглоямочный. Нет никаких сомнений, что данная традиция связана с керамикой имендяшевского типа, локализующегося на территории среднего течения р. Белая и характеризующегося очень схожим, а порой аналогичным орнаментом и формами сосудов (Матвеева, 1971, с. 129; Генинг, 1972, с. 245).

В коллекции городища, также встречены сосуды бахмутинской культуры, украшенные оттисками гребенчатого штампа, как в сочетании с круглоямочным - $4(0,80 \%)$, так и без него - $2(0,40 \%)$. Насечки по венчику в различных комбинациях с другими элементами орнамента встречены в общей сложности на 68 (13,60\%) фрагментах сосудов. Подобный тип керамики, встречается на большинстве поселений бахмутинской культуры в Уфимско-Бельском междуречье и вероятно является свидетельством внешнего импульса связанного с керамическими традициями зауральского населения, в частности бакальского (Гущина, Боталов, 2016, с. 394, рис. 31-33).

Примесью в формовочных массах керамики бахмутинского типа на Барьязинском городище чаще всего выступает песок - 415 (83,00\%). Песок некалиброванный (от пыле-

Таблица 2. Элементы и композиции орнамента, и их распределение по культурным группам Table 2. Elements and compositions of the ornament, and their distribution by cultural groups

\begin{tabular}{|c|c|c|c|c|c|c|c|c|c|c|}
\hline Элементы и композиции орнамента & \multicolumn{2}{|c|}{ Общее } & \multicolumn{2}{|c|}{ Бахмутино } & \multicolumn{2}{|c|}{ Ананьино } & \multicolumn{2}{|c|}{ Пьяноборье } & \multicolumn{2}{|c|}{ Мазунино } \\
\hline Ямка бессистемно & 276 & $46,00 \%$ & 276 & $55,20 \%$ & & & & & & \\
\hline Ямка & 131 & $21,83 \%$ & 112 & $22,40 \%$ & & & 3 & $27,27 \%$ & & \\
\hline Ямка+насечки по венчику & 43 & $7,17 \%$ & 35 & $7,00 \%$ & & & & & & \\
\hline $\begin{array}{l}\text { Ямка бессистемно+насечки по } \\
\text { венчику }\end{array}$ & 29 & $4,83 \%$ & 28 & $5,60 \%$ & & & & & & \\
\hline Насечки по венчику & 27 & $4,50 \%$ & 1 & $0,20 \%$ & & & & & 3 & $25,00 \%$ \\
\hline Ямка+ёлочка & 15 & $2,50 \%$ & 15 & $3,00 \%$ & & & & & & \\
\hline Ямка горизонт. пояс & 14 & $2,33 \%$ & & & 6 & $30,00 \%$ & 8 & $72,73 \%$ & 1 & $8,33 \%$ \\
\hline Вдавления (не круглые) & 10 & $1,67 \%$ & 1 & $0,20 \%$ & & & & & 6 & $50,00 \%$ \\
\hline Ямка+вдавления & 10 & $1,67 \%$ & 10 & $2,00 \%$ & & & & & & \\
\hline Ямка+шнуровой & 10 & $1,67 \%$ & & $0,00 \%$ & 10 & $50,00 \%$ & & & & \\
\hline Ёлочка & 9 & $1,50 \%$ & 9 & $1,80 \%$ & & & & & & \\
\hline Гребенка & 5 & $0,83 \%$ & 2 & $0,40 \%$ & 1 & $5,00 \%$ & & & & \\
\hline Ямка+гребенка & 5 & $0,83 \%$ & 4 & $0,80 \%$ & & & & & & \\
\hline Вдавления+насечки по венчику & 4 & $0,67 \%$ & & & & & & & 2 & $16,67 \%$ \\
\hline Шнуровой & 3 & $0,50 \%$ & & & 3 & $15,00 \%$ & & & & \\
\hline Ёлочка+насечки по венчику & 2 & $0,33 \%$ & 1 & $0,20 \%$ & & & & & & \\
\hline Ямка бессистемно+ёлочка & 2 & $0,33 \%$ & 2 & $0,40 \%$ & & & & & & \\
\hline Ямка+ёлочка+насечки по венчику & 2 & $0,33 \%$ & 2 & $0,40 \%$ & & & & & & \\
\hline Ряды ямок (два и более) & 1 & $0,17 \%$ & & & & & & & & \\
\hline Ямка бессистемно+гребенка & 1 & $0,17 \%$ & 1 & $0,20 \%$ & & & & & & \\
\hline Ямка+гребенка+насечки по венчику & 1 & $0,17 \%$ & 1 & $0,20 \%$ & & & & & & \\
\hline Общее & 600 & $100,00 \%$ & 500 & $100,00 \%$ & 20 & $100,00 \%$ & 11 & $100,00 \%$ & 12 & $100,00 \%$ \\
\hline
\end{tabular}




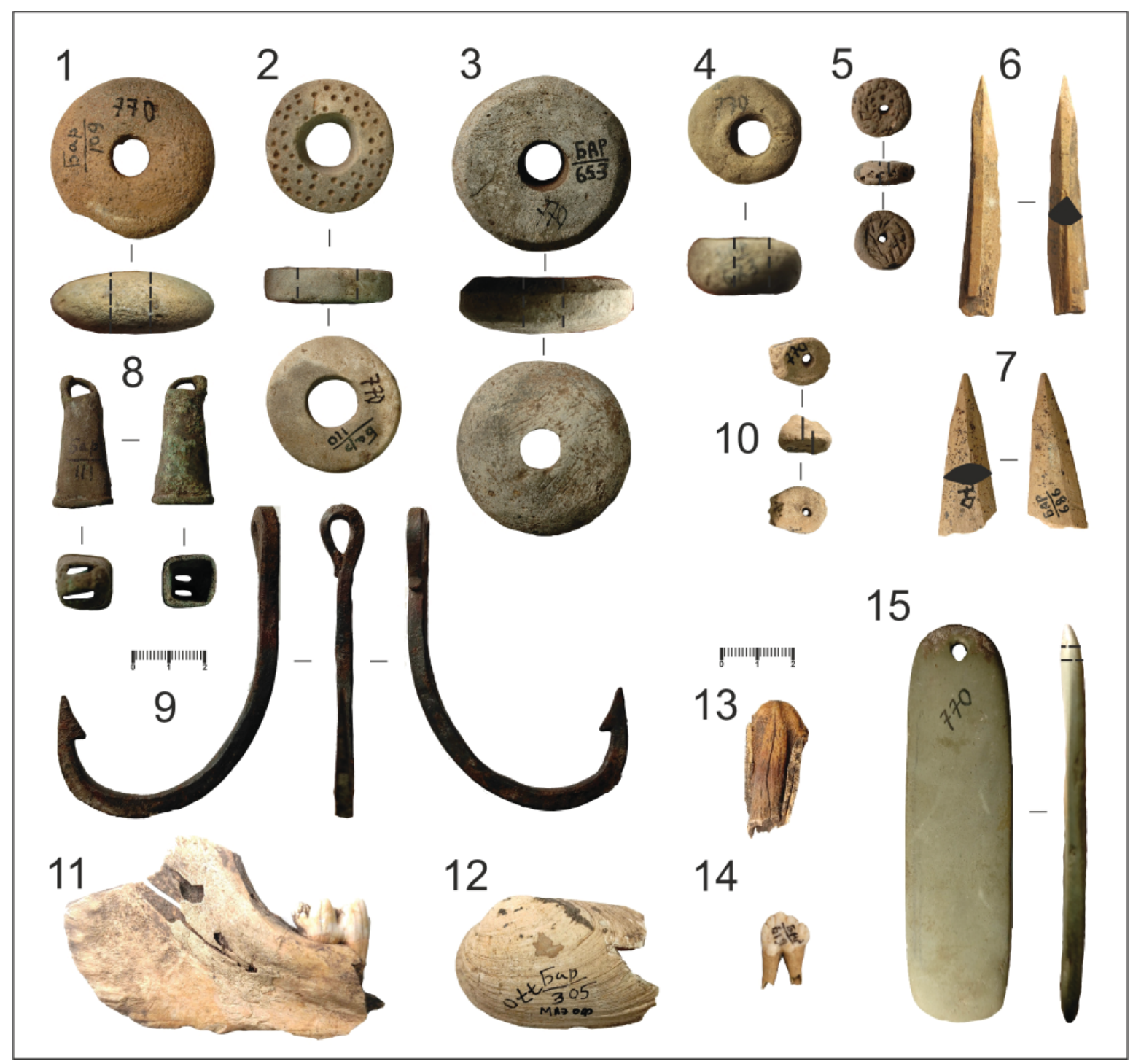

Рис. 5 Индивидуальные находки:

1-5, 10 керамика, 6,7, 11, 13, 14 - кость; 8 - бронза; 9 - железо; 12 - раковина; 15 - камень

Fig. 5 Individual finds:

1-5, 10 ceramics; $6,7,11,13,14$ - bone; 8 - bronze; 9 - iron; 12 - shell; 15 - stone

видных включений, до больших галек размерами 3-5 мм), встречаются окатанные и не окатанные фракции, поэтому дифференциация на песок и дресву затруднительна. В 47 (9,40\%) случаях примесь представлена некалиброванными включениями песка и раковины, 35 (7,00\%) сосудов имеют исключительно раковину в виде примеси. В ходе осмотра были встречены включения органики, в виде мелких фрагментов растительности (стебли растений), которые, вероятно, могут быть естественными.

Проведенное исследование позволяет установить, что на Барьязинском городище, как и на многих других поселениях Уфимско-Бельского междуречья, встречены керамические традиции населения ананьинской, пьяноборской, мазунинской и бахмутинской археологических культур. Судя по количеству и разнообразию керамической коллекции, исследованная В.А. Ивановым часть площадки памятника наиболее активно использовалась бахмутинским населением. Данные о том, когда и кем были возведены укрепления в настоящее время отсутствуют, при этом специфика внешней сохранившейся конструкции первого и второго валов наиболее характерна именно для укреплений бахмутинской культуры (Колонских, 2017, с. 64). Стоит заметить, что наряду с укрепленным поселением в непосредственной близости находится одноименное селище бахмутинской культуры, при этом округу городища можно считать слабо изученной в археологическом плане, потому 
Таблииа 3. Состав формовочных масс керамической коллекции Table 3. Composition of the molding materials of the ceramic collection

\begin{tabular}{|c|c|c|c|c|c|c|c|c|c|c|}
\hline Примеси & \multicolumn{2}{|c|}{ обшее } & \multicolumn{2}{|c|}{ Бахмутино } & \multicolumn{2}{|c|}{ Ананьино } & \multicolumn{2}{|c|}{ Пьяноборье } & \multicolumn{2}{|c|}{ Мазунино } \\
\hline Песок & 510 & $69,01 \%$ & 415 & $83,00 \%$ & & & & & 1 & $4,17 \%$ \\
\hline Раковина & 149 & $20,16 \%$ & 35 & $7,00 \%$ & 20 & $100,00 \%$ & 11 & $100,00 \%$ & 10 & $41,67 \%$ \\
\hline Песок+раковина & 61 & $8,25 \%$ & 47 & $9,40 \%$ & & & & & 1 & $4,17 \%$ \\
\hline Раковина+органика & 13 & $1,76 \%$ & & & & & & & & \\
\hline не определено & 3 & $0,41 \%$ & & & & & & & & \\
\hline Песок+дресва & 1 & $0,14 \%$ & 1 & $0,20 \%$ & & & & & & \\
\hline Песок+органика & 1 & $0,14 \%$ & 1 & $0,20 \%$ & & & & & & \\
\hline Песок+шамот & 1 & $0,14 \%$ & 1 & $0,20 \%$ & & & & & & \\
\hline Обшее & 739 & $100,00 \%$ & 500 & $100,00 \%$ & 20 & $100,00 \%$ & 11 & $100,00 \%$ & 12 & $50,00^{\circ}$ \\
\hline
\end{tabular}

как ближайшие поселения расположены на удалении 9-10 км на противоположном берегу р. Быстрый Танып.

Индивидуальные находки в коллекции представлены пятью глиняными пряслицами (одно орнаментировано круглыми ямочными вдавлениями, другое насечками) с округлым или подпрямоугольным профилем сечения (рис. 5: 1-5 ), фрагментами двух костяных черешковых наконечников стрел ромбовидной и вероятно пятиугольной формы сечения (рис. 5: 6-7) точильным бруском из уплощенной гальки с отверстием (рис. 5,:15), фрагментом глиняной пронизки (рис. 5,10$)$, раковиной речного моллюска (рис. 5: 12), двумя фрагментами зубов животного и фрагментом челюсти животного (предположительно свиньи) (рис. 5: 11, 13 - 14). Среди материалов раскопок хранится рыболовный крючок, выполненный из железного прута подпрямоугольного сечения, ушко загнуто и находится в одной плоскости с крючком (рис. 5: 9). Судя по хорошей сохранности, а также отсутствию аналогий, в синхронных городищу материалах, рыболовный крючок может быть не связан с культурным слоем городища и относится к эпохи Нового, либо Новейшего времени. Наиболее информативным предметом является литая бронзовая полая колоколовидная подвеска с петлёй для подвешивания и валиком в нижней части (рис. 5: 8). Подобные подвески хорошо известны в материалах
Бирского, Бахмутинского, Югамашевского и Старо-Кабановского могильников УфимскоБельского междуречья, датируются 5 в. н.э. и могут быть соотнесены со слоем бахмутинского времени (Васюткин, 1975, с. 30-31, 47-48, 70, рис. 71, 128, 179; Васюткин, Останина, 1986 , с. 67,90 , таб. $16,11,12$; Султанова, 2000 , с. 25 , рис. 7,15 ; Останина, 1997, с. 282-283).

Керамическая коллекция бахмутинской культуры вполне представительна, а полученные в ходе исследования данные позволяют получить принципиальные выводы. Как и на большинстве других поселений бахмутинская керамика Барьязинского городища, имеет 4 - 5 ведущих типов морфологических форм сосудов, аналогичным является характер орнаментации, как в плане элементов и композиций, так и в плане их количественного соотношения внутри коллекции. При этом, состав формовочных масс бахмутинских поселений в нижнем течении р. Быстрый Танып, имеет примесь в виде раковины, которая отсутствует, либо встречается значительно реже на поселениях среднего течения рр. Быстрый Танып и Белая (Колонских, 2020, с. 81), что может быть обосновано наличием локальной традиции изготовления подобной керамики, либо близости к территории широкого распространения гончарных традиций мазунинского населения.

\section{Примечание:}

${ }^{1}$ Выражаю благодарность автору раскопок д.и.н., профессору В.А. Иванову за возможность публикации материалов его исследований, а также всемерную помощь и поддержку в подготовке данной статьи.

\section{ЛИТЕРАТУРА}

Агеев Б.Б. Научный отчет об итогах полевых исследований в 1988 г. Уфа, 1989 / НА УФИЦ РАН, 1989. 
Акбулатов И.М. Научный отчет об итогах инвентаризации археологических памятников Калтасинского района Республики Башкортостан. Уфа, 2010 // Архив научно-производственного центра по охране и использованию недвижимых объектов культурного наследия Республики Башкортостан, 2010.

Бугров Д.Г. Поселения пьяноборской культуры в Икско-Бельском междуречье. Дисс. ... канд. ист. наук. Казань, 2006. 350 с.

Васюткин C.M. Отчет о работе первого отряда археологической экспедиции Башгосуниверситета в 1975 году. Уфа, 1976 // Археологическая лаборатория Башкирского государственного университета Ф. 6. Д. 15.

Васюткин С.М., Останина Т.И. Старо-Кабановский могильник - памятник мазунинской культуры в Северной Башкирии // Вопросы истории и культуры Удмуртии / Сост., науч. ред. Т.И. Останина. Устинов: Удмуртия, 1986. С. 64-125.

Генинг В.Ф. Южное Приуралье в III-VII вв. н.э. (проблема этноса и его происхождения) // Проблемы археологии и древней истории угров / Отв. ред. А.П. Смирнов, В.Н. Чернецов, И.Ф. Эрдели. М.: Наука, 1972. С. 221-295.

Гущина Е.В., Боталов С.Г. Большое Бакальское городище // Археология Южного Урала. Лес, лесостепь (проблемы культурогенеза). ) / Ред. С.Г. Боталов и др. Челябинск: ООО ЦИКР «Рифей», 2016. C. 361-409.

Иванов B.A. Отчет об исследовании памятников 1 тыс. н.э. на севере Башкирской АСССР, по Открытому листу № 356. Уфа, 1975 // АЛ БашГУ. Ф. 6, д. 14.

Колонских А.Г. Научный отчет об итогах разведочных археологических исследований на территории Дюртюлинского, Калтасинского, Янаульского и Бураевского районов Республики Башкортостан в 2015 г. Уфа, 2017. 181 с. / Научный архив Института этнологических исследований им. Р.Г. Кузеева УФИЦ РАН.

Колонских А.Г. Укрепленные поселения Уфимско-Бельского междуречья // Вестник Вятского государственного университета. 2017. № 12. С. 62-67.

Колонских А.Г. Керамический комплекс Кансияровского городища (по материалам коллекций археологических фондов ИЭИ УФИЦ РАН) // История и педагогика естествознания. 2020. №3-4. С. 75-82.

Матвеева Г.И. Лесная и лесостепная Башкирия во второй половине I тысячелетия н.э. // АЭБ. Т. IV. / Отв. ред. Ю.В. Бромлей, Р.Г. Кузеев. Уфа: БФ АН СССР, 1971. С. 129-134.

Мажитов Н.А. Иллюстрации к отчету за 1960 год. Уфа, 1960 / НА УФИЦ РАН. Ф. 3. Оп. 2. Д. 489.

Морозов Ю.А. Научный отчет о работе разведочного отряда Башкирской археологической экспедиции в 1964 году. Уфа, 1965 / НАО ИА РАН. Ф. 1. Р. 1. № 2887.

Овсянников В.В. Ананьинская культура VIII-III вв. до н.э.: История башкирского народа. Т. 1 / Отв. ред. В.В. Овсянников, В.К. Федоров, Ф.Г. Хисамитдинова. М.: Наука, 2009. С. 213-223.

Останина Т.И. Население Среднего Прикамья в III-V вв. Ижевск: УИИЯЛ, 1997. 326 с.

Султанова А.Н. Бирский могильник: историко-археологическое исследование. Дис... канд. ист. наук. Уфа, 2000. 225 с.

\section{Информация об авторе:}

Колонских Александр Геннадьевич, младший научный сотрудник, Институт этнологических исследований им. Р.Г. Кузеева УФИЦ РАН (г. Уфа, Россия); kontrobazzz@mail.ru

\section{REFERENCES}

Ageev, B. B. 1989. Nauchnyi otchet ob itogakh polevykh issledovanii v 1988 g. (Scientific report on the Results of Field Studies in 1988) Ufa. Scientific archive of the Ufa Federal Research Center of the Russian Academy of Sciences (in Russian).

Akbulatov, I. M. 2010. Nauchnyi otchet ob itogakh inventarizatsii arkheologicheskikh pamiatnikov Kaltasinskogo raiona Respubliki Bashkortostan (Scientific Report on the Results of the Inventory of Archaeological Sites in the Kaltasinsky District of the Republic of Bashkortostan). Ufa. Archive of the Research and Production Center for the Protection and Use of Immovable Objects of Cultural Heritage of the Republic of Bashkortostan (in Russian).

Bugrov, D. G. 2006. Poseleniya p'yanoborskoy kul'tury v Iksko-Bel'skom mezhdurech'e (Settlements of the Pyany Bor Culture in the Ik-Belaya Interfluve). Thesis of the Candidate of Historical Sciences. Kazan (in Russian). 
Vasyutkin, S. M. 1976. Otchet o rabote pervogo otriada arkheologicheskoi ekspeditsii Bashgosuniversiteta $v 1975$ godu (Report on the Work of the First Detachment of the Archaeological Expedition of Bashkir State University in 1975). Ufa. Archaeological laboratory of the Bashkir State University. F. 6. D. 15 (in Russian).

Vasyutkin, S. M., Ostanina, T. I. 1986. In Ostanina, T. I. (ed.). Voprosy istorii i kul tury Udmurtii (Issues of History and Culture of Udmurtia). Ustinov: Udmurtiia, 64-125 (in Russian).

Gening, V. F. 1972. In Smirnov, A. P., Chernetsov, V. N., Erdélyi, I. F. (eds.). Problemy arkheologii i drevnei istorii ugrov (Issues of the Archaeology and Ancient History of the Ugric Peoples). Moscow: "Nauka" Publ., 221-295 (in Russian).

Gushchina, E. V., Botalov, S. G. 2016. In Botalov, S. G. (ed.). Arkheologiia Iuzhnogo Urala. Les, lesostep' (problemy kul'turogeneza) (Archaeology of the Southern Urals. Forest, Forest-Steppe (issues of cultural genesis). Series: Ethnic genesis of Ural peoples. Cheliabinsk: "Riphean" Publ., 361-409 (in Russian).

Ivanov, V. A. 1975. Otchet ob issledovanii pamiatnikov 1 tys. n.e. na severe Bashkirskoi ASSSR, po Otkrytomu listu № 356 (Report on the Study of the Monuments of the 1st Millennium AD in the North of the Bashkir ASSR according to Open Sheet No. 356) Ufa. Archaeological Laboratory of Bashkir State University. F. 6, d. 14 (in Russian).

Kolonskikh, A. G. 2017. Nauchnyi otchet ob itogakh razvedochnykh arkheologicheskikh issledovanii na territorii Diurtiulinskogo, Kaltasinskogo, Ianaul'skogo i Buraevskogo raionov Respubliki Bashkortostan v 2015 g. (Scientific Report on the Results of Exploratory Archaeological Studies on the Territory of Dyurtyulinsky, Kaltasinsky, Yanaulsky and Buraevsky Districts of the Republic of Bashkortostan in 2015). Ufa. Scientific archive of the Institute of Ethnological Research named after V.I. R.G. Kuzeeva (in Russian).

Kolonskikh, A. G. 2017. In Vestnik Vyatskogo gosudarstvennogo universiteta (Bulletin of Vyatka State University) 12, 62-67 (in Russian).

Kolonskikh, A. G. 2020. In Istoriia i pedagogika estestvoznaniia (History and Pedagogy of Natural Science) (3-4), 75-82 (in Russian).

Matveeva, G. I. 1971. In Bromlei, Yu. V., Kuzeev, R. G. (eds.). Arkheologiia i etnografiia Bashkirii (Archaeology and Ethnography of Bashkiria) IV. Ufa: Bashkirian Branch of the USSR Academy of Sciences, 129-134 (in Russian).

Mazhitov, N. A. 1960. Illiustratsii $k$ otchetu za 1960 god (Illustrations for the Report of 1960). Ufa. Scientific Archive of the Ufa Federal Research Center of the Russian Academy of Sciences. F. 3. Inv. 2. Doisser 489 (in Russian).

Morozov, Yu. A. 1965. Nauchnyi otchet o rabote razvedochnogo otriada Bashkirskoi arkheologicheskoi iekspeditsii v 1964 godu (Scientific Report on the Work of the Exploration Detachment of the Bashkir Archaeological Expedition in 1964) Ufa. Archive of the Institute of Archaeology of the RAS. F. 1. R. 1. № 2887 (in Russian).

Ovsyannikov, V. V. 2009. In Ovsyannikov, V. V., Fedorov, V. K., Khisamitdinova, F. G. (eds.). Istoriia bashkirskogo naroda: $v 7$ tomakh (History of the Bashkir People in 7 Volumes) 1. Moscow: "Nauka" Publ., 213-223 (in Russian).

Ostanina, T. I. 1997. Naselenie Srednego Prikam'ia v III-Vvv. (Population of the Middle Kama Region in $3^{\text {rd }}-5^{\text {th }}$ Centuries $A D$ ). Izhevsk: Udmurt Institute of the History, Language and Literature, Ural Branch of the Russian Academy of Sciences (in Russian).

Sultanova, A. N. 2000. Birskii mogil'nik: istoriko-arkheologicheskoe issledovanie (Birsk Burial Ground: Historical and Archaeological Study). Diss. of Historical Sciences Ufa (in Russian).

\section{About the Author:}

Kolonskikh Aleksandr G. Institute of Ethnological Studies of R.G. Kuzeev Ufa Scientific Center, Russian Academy of Sciences. K. Marx str., 6, 45007, Ufa, Russian Federation; kontrobazzz@mail.ru

Статья поступила в журнал 01.10.2021 г. Статья принята к публикации 01.12.2021 г. 